\title{
Genetic evidence from Indian red jungle fowl corroborates multiple domestication of modern day chicken Sriramana Kanginakudru ${ }^{\dagger 1,3}$, Muralidhar Metta ${ }^{\dagger 1}$, RD Jakati ${ }^{2}$ and J Nagaraju*1
}

Address: ${ }^{1}$ Laboratory of Molecular Genetics, Centre for DNA Fingerprinting and Diagnostics, ECIL-Road, Nacaharam, Hyderabad, 500076, India ,${ }^{2}$ Van Bhavan, Plot No 6-18, Sector 6, Panchakula, Haryana, India and ${ }^{3}$ Department of Neurobiology, University of Massachusetts Medical School, Worcester, MA 01605, USA

Email: Sriramana Kanginakudru - sriramana@cdfd.org.in; Muralidhar Metta - muralidharmetta@gmail.com;

RD Jakati - jakatis654@yahoo.co.in; J Nagaraju* - jnagaraju@cdfd.org.in

* Corresponding author †Equal contributors

Published: 10 June 2008

BMC Evolutionary Biology 2008, 8:174 doi:10.1 |86/I47|-2/48-8-174

This article is available from: http://www.biomedcentral.com/I47I-2/48/8/I74

(c) 2008 Kanginakudru et al; licensee BioMed Central Ltd.

This is an Open Access article distributed under the terms of the Creative Commons Attribution License (http://creativecommons.org/licenses/by/2.0), which permits unrestricted use, distribution, and reproduction in any medium, provided the original work is properly cited.
Received: 19 October 2006

Accepted: 10 June 2008

\begin{abstract}
Background: Domestication of chicken is believed to have occurred in Southeast Asia, especially in Indus valley. However, non-inclusion of Indian red jungle fowl (RJF), Gallus gallus murghi in previous studies has left a big gap in understanding the relationship of this major group of birds. In the present study, we addressed this issue by analyzing 76 Indian birds that included $56 \mathrm{G}$. g. murghi (RJF), 16 G. g. domesticus (domestic chicken) and $4 \mathrm{G}$. sonneratii (Grey JF) using both microsatellite markers and mitochondrial $D$-loop sequences. We also compared the $D$-loop sequences of Indian birds with those of 779 birds obtained from GenBank.

Results: Microsatellite marker analyses of Indian birds indicated an average $F_{S T}$ of 0.126 within $G$. g. murghi, and 0.154 within G. g. domesticus while it was more than 0.2 between the two groups. The microsatellite-based phylogenetic trees showed a clear separation of $G$. g. domesticus from $G$. $g$. murghi, and $G$. sonneratii. Mitochondrial DNA based mismatch distribution analyses showed a lower Harpending's raggedness index in both G. g. murghi $(0.001515)$ and in Indian G. g. domesticus $(0.0149)$ birds indicating population expansion. When meta analysis of global populations of 855 birds was carried out using median joining haplotype network, 43 Indian birds of $G$. g. domesticus (19 haplotypes) were distributed throughout the network sharing haplotypes with the RJFs of different origins.
\end{abstract}

Conclusion: Our results suggest that the domestication of chicken has occurred independently in different locations of Asia including India. We found evidence for domestication of Indian birds from G. g. spadiceus and G. g. gallus as well as from G. g. murghi, corroborating multiple domestication of Indian and other domestic chicken. In contrast to the commonly held view that RJF and domestic birds hybridize in nature, the present study shows that $G$. g. murghi is relatively pure. Further, the study also suggested that the chicken populations have undergone population expansion, especially in the Indus valley. 


\section{Background}

Archeological findings have indicated that the 'mother of all poultry' is the Southeast (SE) Asian Red jungle fowl (RJF) (Gallus gallus). Since domestication of chicken has been observed at the Indus valley as early as 3,200 BC, it is believed to be the epicenter of chicken domestication [1]. However, later day excavations in Peiligan Neolithic sites of China have raised questions about the exclusive domestication at Indus valley, suggesting alternate and possibly earlier domestication centers [2]. It is proposed that G. gallus, the wild RJF found in the forests of SE Asia and India, spread to other parts of the world when people domesticated the chicken, resulting in many chicken breeds $[3,4]$. Subsequent to domestication, the extensive breeding programmes have resulted in sixty or so breeds of chicken representing four distinct lineages: egg-type, game, meat-type and bantam [5]. While some authors suggest monophyletic origin of domestic chicken $[6,7]$, others provide evidence for multiple and independent domestication events [8]. Such inconsistent observations are attributable to the fact that the initial studies were done with relatively small set of samples. In all these reported studies the native RJFs of Indian sub-continent, G. g. murghi were not represented in the analyses due to lack of sequence or molecular marker information on this group of birds.

Taxonomically, genus Gallus is composed of four species, G. gallus (RJF), G. lafayettei (Lafayette's JF), G. varius (Green JF) and G. sonneratii (Grey JF - GJF). Presently there are 5 sub-species of RJF, G. g. gallus (SE Asian RJF), and G. g. spadiceus, G. g. bankiva, G. g. murghi (Indian RJF) and G. g. jabouillei [9]. These classifications are mainly based on phenotypic traits and geographic distribution of the populations. In literature, wild and domesticated birds are often referred to as 'fowls' and 'chicken', respectively. The domestic chicken is considered either as a subspecies of RJF (G. g. domesticus) or as a separate species, G. domesticus. However, tight clustering of the different subspecies discounts this existing taxonomical hierarchy [6] rendering sub-species status within RJF redundant.

Besides the taxonomical intricacies, the researchers are also concerned about the genetic integrity and conservation status of the RJF in the wild and those held in avicultural collections. It is suspected that the domestic chicken is hybridizing with the wild RJF resulting in erosion of genetic purity of the wild birds $[4,10,11]$. Most of these earlier studies are based on either phenotypic characters or DNA analyses confined to small samples. Phylogenetic analyses of mitochondrial D-loop sequence and nuclear genes have indicated possible hybridization between GJF$\mathrm{RJF} /$ domestic birds [11]. In the light of these reports it is important to assess the genetic uniqueness of Indian RJFs not only from conservation point of view, but also for using them in population studies.

It is well known that the patterns of genetic differences can reveal the demographic history of the population under study. Since changes in population size leave characteristic molecular signatures, by measuring such changes one can reconstruct the population history. Mismatch distributions, also known as 'pairwise differences' give information on genetic differences between pairs of subjects and can be used to understand the population history [12]. Mitochondrial DNA (mtDNA) is inherited maternally [13] and is often employed in population genetic analyses due to its high copy number, haploid nature and absence of/rare recombination events [14]. A recent study involving the analysis of chicken mitochondrial DNA sequence from pre-historical samples pointed pre-columbian Polynesian origin of American breeds [15], thus suggesting the importance of mitochondrial D-loop sequence in determining the history of chicken domestication. Microsatellite markers, on the other hand, are nuclear markers and are used extensively in population genetic analyses because they are highly polymorphic, ubiquitously distributed throughout the genome, are having high mutation rates, co-dominant in nature, selectively neutral and are amenable to PCR-based high through-put analysis [16]. Hilel et al. [17] characterized 52 chicken breeds using 22 microsatellite markers and concluded that the origin of domestic chicken to be from RJFs, as supported by mt DNA analyses [8].

In all the earlier studies these two marker systems have been used independently to study chicken populations $[7,17-19]$. In the present study we have combined the results emanating from these two informative marker systems to address the questions relating to (i) evolutionary status of Indian RJF and chicken and (ii) extent of gene flow between Indian RJF and chicken, RJF-GJF in comparison to the world population.

\section{Results \\ Genetic identity of Indian fowls}

In the present study, phylogenetic and demographic profiling analyses were carried out using 76 Indian birds that belong to seven populations. We employed 11 microsatellite markers and also sequenced 650 bp of hyper variable region (D-loop) of mitochondrial genomes of two species of fowls namely G. sonneratii $(n=4)$ and G. gallus, which includes two subspecies G. g. murghi, $(\mathrm{n}=56)$ and G. g. domesticus $(\mathrm{n}=16)$.

Totally there were 197 alleles from 11 microsatellite loci, of which, 106 were from G. g. murghi, and 59 were from G. g. domesticus chicken. The locus MCW5 gave the maximum number of alleles in G. g. murghi and in G. sonner- 
Table I: Microsatellite loci and PCR conditions used in the present study, and population-wise number of alleles obtained for Indian chicken. Original references are listed in the table.

\begin{tabular}{|c|c|c|c|c|c|c|c|c|}
\hline \multirow[t]{2}{*}{ Locus } & \multirow[t]{2}{*}{ Repeat motif } & \multirow[t]{2}{*}{ Allele Size range } & \multirow[t]{2}{*}{$\operatorname{Tm}{ }^{\circ} \mathrm{C}$} & \multirow[t]{2}{*}{$\mathrm{MgCl}_{2}$} & \multicolumn{3}{|c|}{ Total no. of alleles* } & \multirow[t]{2}{*}{ Reference } \\
\hline & & & & & G. sonneratii & G. g. murghi & G. g. domesticus & \\
\hline ADL210 & $(A C)_{15}$ & $116-130$ & 46 & $1.5 \mathrm{mM}$ & 1 & 2 & 5 & {$[4 I]$} \\
\hline CALBI & $(\mathrm{T})_{25}$ & $76-106$ & 55 & $2.5 \mathrm{mM}$ & 2 & 3 & 3 & {$[42]$} \\
\hline HSF3A & $(G A G)_{10}$ & $230-259$ & 55 & $\mathrm{I} \mathrm{mM}$ & 2 & 12 & 8 & [42] \\
\hline HUJI & $(\mathrm{GT})_{23}$ & $150-180$ & 55 & $1.5 \mathrm{mM}$ & 4 & 11 & 7 & [43] \\
\hline MCWI & $(\mathrm{GT})_{9}$ & $|57-| 7 \mid$ & 62 & $1.5 \mathrm{mM}$ & 1 & 6 & 5 & {$[42]$} \\
\hline MCW305 & $(\mathrm{GT})_{13}$ & $250-275$ & 55 & $1.5 \mathrm{mM}$ & 3 & 3 & 7 & [43] \\
\hline MCW306 & $(\mathrm{AT})_{11}$ & $142-176$ & 55 & $1.5 \mathrm{mM}$ & 4 & 9 & 6 & [43] \\
\hline MCW4 & $(\mathrm{TG})_{8}$ & $146-188$ & 67 & $2.5 \mathrm{mM}$ & 2 & 15 & 3 & [18] \\
\hline MCW5 & $\begin{array}{c}(\mathrm{TG})_{6} \mathrm{AA}(\mathrm{TG})_{6}(\mathrm{~A})_{15} \\
(\mathrm{GA})_{2}(\mathrm{GAA})_{21}\end{array}$ & $184-263$ & 62 & $1.5 \mathrm{mM}$ & 4 & 18 & 9 & [18] \\
\hline MYCN & $(\mathrm{TG})_{17}$ & $174-210$ & 69 & $2 \mathrm{mM}$ & 4 & 12 & 5 & [43] \\
\hline VITIIG2 & $(\text { TTTG })_{6}$ & $143-179$ & 51 & $3 \mathrm{mM}$ & 5 & 15 & 1 & {$[4 I]$} \\
\hline Total & & & & & 32 & 106 & 59 & \\
\hline
\end{tabular}

*No. of alleles obtained in the present study.

atii, while VITIIG2 locus revealed the maximum number of alleles in G. g. domesticus (Table 1). The total number of private alleles was maximum in G. g. murghi followed by G. g. domesticus and G. sonneratii, respectively. Populationwise mean number of alleles per locus ranged from 2.91 (G. sonneratii) to 6.09 (Birshi Kargah population of G. $g$. murghi, B-RJF), with a mean heterozygosity ranging from 0.481 (K-RJF) to 0.600 (B-RJF).

When the 76 birds were subdivided into seven groups (see methods section for the grouping of birds) and analyzed for Hardy-Weinberg equilibrium (HWE), of the 77 combinations ( 7 groups $\times 11$ loci) 32 deviated from HWE, with 22 deviations occurring in G. g. murghi alone and 8 in G. g. domesticus group (See Additional file 1). We speculate that G. g. murghi is probably not in HWE because of inbreeding within the fragmented populations. The low $\mathrm{F}_{\mathrm{ST}}$ values among G. g. murghi as compared to G. g. domesticus birds also suggested possible inbreeding within G. $g$. murghi populations. The average $\mathrm{F}_{\mathrm{ST}}$ was 0.126 within $G$. g. murghi, while it was 0.154 within G. g. domesticus (Table $2)$. The AMOVA estimation based on 99 permutations using GenAlEx showed a significant $(P=0.01)$ within population variation ( $66 \%$ in $7 \mathrm{G}$ and $69 \%$ in $2 \mathrm{G}$ population). Upon grouping the 72 Indian birds as domestic and $\mathrm{RJF}$, the microsatellite markers showed a significant variation 'among the groups' (i.e. domestic-RJF, 27\%, $P=0.01$ ) than 'within the group' $(17 \%, P=0.01)$.

Population-wise Nei's genetic distance calculated using GenAlEx program showed a higher average distance between G. sonneratii and G. g. domesticus (2.099) than between G. sonneratii - G. g. murghi (0.758) and G. $g$. murghi - G. g. domesticus (1.695) combinations (Additional file 1). Intra-population average distances were lower for both domestic and RJF groups than across the population distances, which is consistent with the observation that among population variation was more than within population variation. The results suggest very rare genetic exchange between the RJF and domestic chicken populations, at least in recent history.

A Maximum Likelihood (ML) tree obtained from the microsatellite data showed a clear separation of G. g. domesticus from the G. g. murghi, with G. sonneratii as an outgroup (Fig. 1a) suggesting the genetic distinctness of G. g. murghi. However, rare instances of hybridization between Indian RJF and domestic birds cannot be excluded in nature as seen in one case (K10-C1, Fig. 1a).

We also constructed a genetic distance based neighborjoining (NJ) tree to obtain the genetic relationship among Indian birds. The result clearly points to the fact that

Table 2: Population pairwise $\mathbf{F}_{\mathrm{ST}}$ values of microsatellite (below diagonal) and mitochondrial D-loop sequence (above diagonal) for 76 Indian chicken classified into 7 groups.

\begin{tabular}{llllllll}
\hline & M-RJF & B-RJF & K-RJF & C & J & M & GJF \\
\hline M-RJF & & 0.098 & 0.095 & 0.277 & 0.418 & 0.329 & 0.777 \\
B-RJF & 0.123 & & 0.128 & 0.342 & 0.41 & 0.339 & 0.798 \\
K-RJF & 0.140 & 0.114 & & 0.505 & 0.627 & 0.502 & 0.844 \\
C & 0.303 & 0.259 & 0.280 & & 0.332 & 0.277 & 0.787 \\
J & 0.311 & 0.246 & 0.306 & 0.164 & & 0.306 & 0.835 \\
M & 0.299 & 0.251 & 0.307 & 0.141 & 0.157 & & 0.824 \\
GJF & 0.210 & 0.190 & 0.218 & 0.316 & 0.327 & 0.302 & \\
\hline
\end{tabular}

Note: RJF - G. g. murghi populations. M - Morni Hill, B - Birshi Kargah, K - Kalesar. C, J and M represent G. g. domesticus from Chicken, Jodhpur and Mirpur Bakshiwala populations. GJF - G. sonneratii (India). 


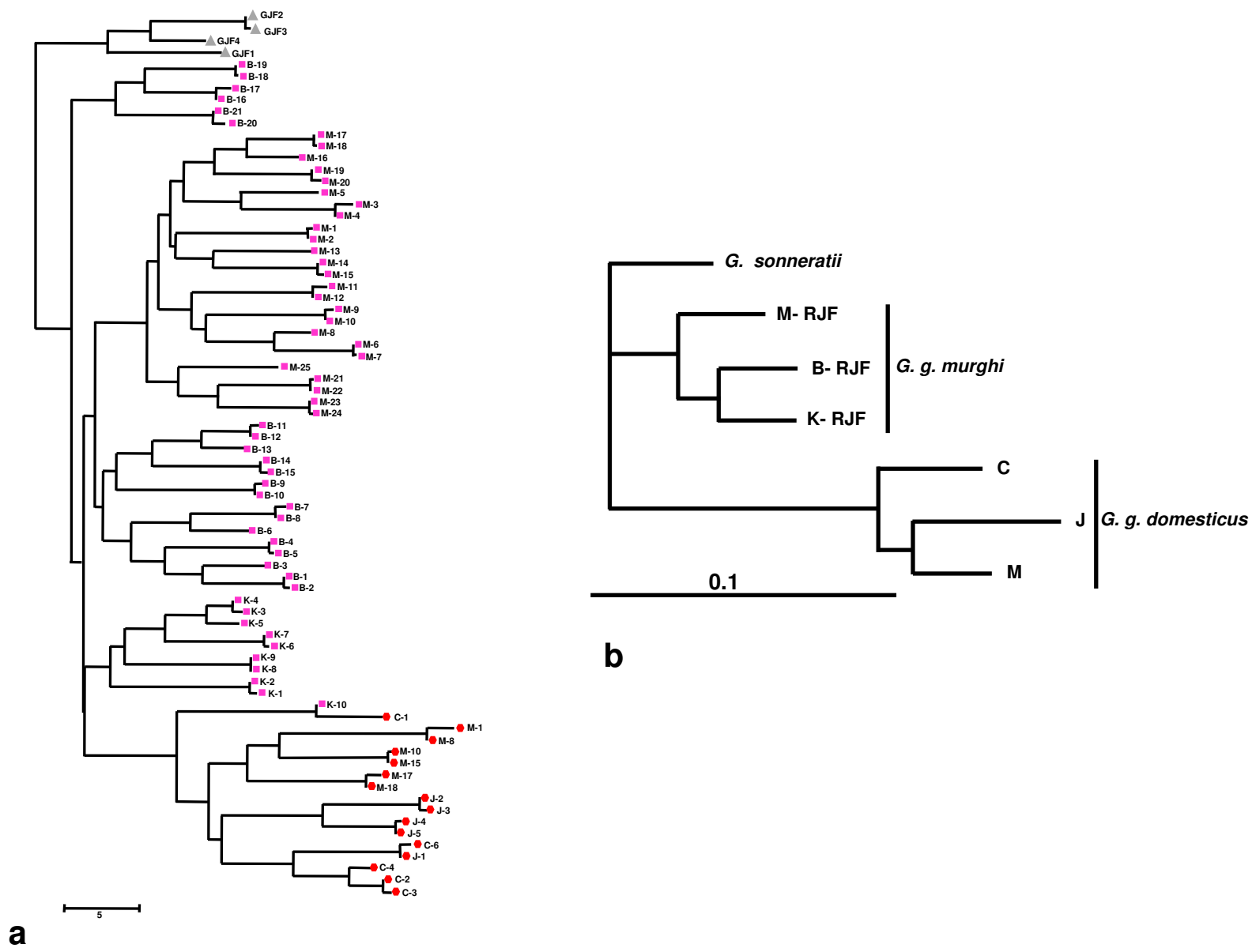

\section{Figure I}

a) A Maximum likelihood phylogenetic tree constructed using microsatellite data of Indian birds. Contml program of Phylip package was used to construct a ML tree. The birds segregate according to the groups as domestic (red hexagonal), RJF (pink square) clades with GJF as an outgroup (grey triangle). Scale indicates the allele frequency. b) A neighbor-joining phylogenetic tree constructed based on genetic distance using microsatellite data of Indian birds. Genetic distance was calculated with GenAIEx program and the distance matrix was used to construct NJ tree in MEGA with K2P parameter. The distinct clades of $G$. g. murghi and $G$. g. domesticus is evident with $G$. sonneratii forming the outgroup. Scale indicates the genetic difference.

hybridization between Indian chicken and Indian RJF G. g. murghi in the wild is extremely rare (Fig. 1b).

To understand the clustering pattern of birds, we also carried out genetic distance based principal component analysis (PCA) (Fig. 2) of domestic and RJF birds, using GenAlEx. The results showed clear segregation of all domestic birds into a single quadrate of the PCA (left upper quadrate in Fig. 2), which did not include any RJF. However, the population of RJFs did not segregate according to the location/population, suggesting the possibility of inbreeding within the RJF populations. This result further supports the absence of hybridization between RJF and domestic birds in India, at least in recent times.
We also sequenced and analyzed $650 \mathrm{bp}$ of the D-loop region of 76 Indian birds to derive the matrilineal population history by using coalescent-based models.

The pairwise $\mathrm{F}_{\mathrm{ST}}$ values calculated using Arlequin were very low within G. g. murghi when compared to G. $g$. domesticus (Table 2). The average $\mathrm{F}_{\mathrm{ST}}$ values were more for G. sonneratii - G. g. domesticus combination than for $G$. sonneratii-G. g. murghi or G. g. murghi - G. g. domesticus combinations. Contrary to microsatellite based analysis, mitochondrial analysis showed a lower mean pairwise $\mathrm{F}_{\mathrm{ST}}$ value for G. sonneratii - G. g. domesticus combination. These results again point out that there is hardly any genetic exchange across the three categories of birds, namely GJF, RJF and domestic birds. 


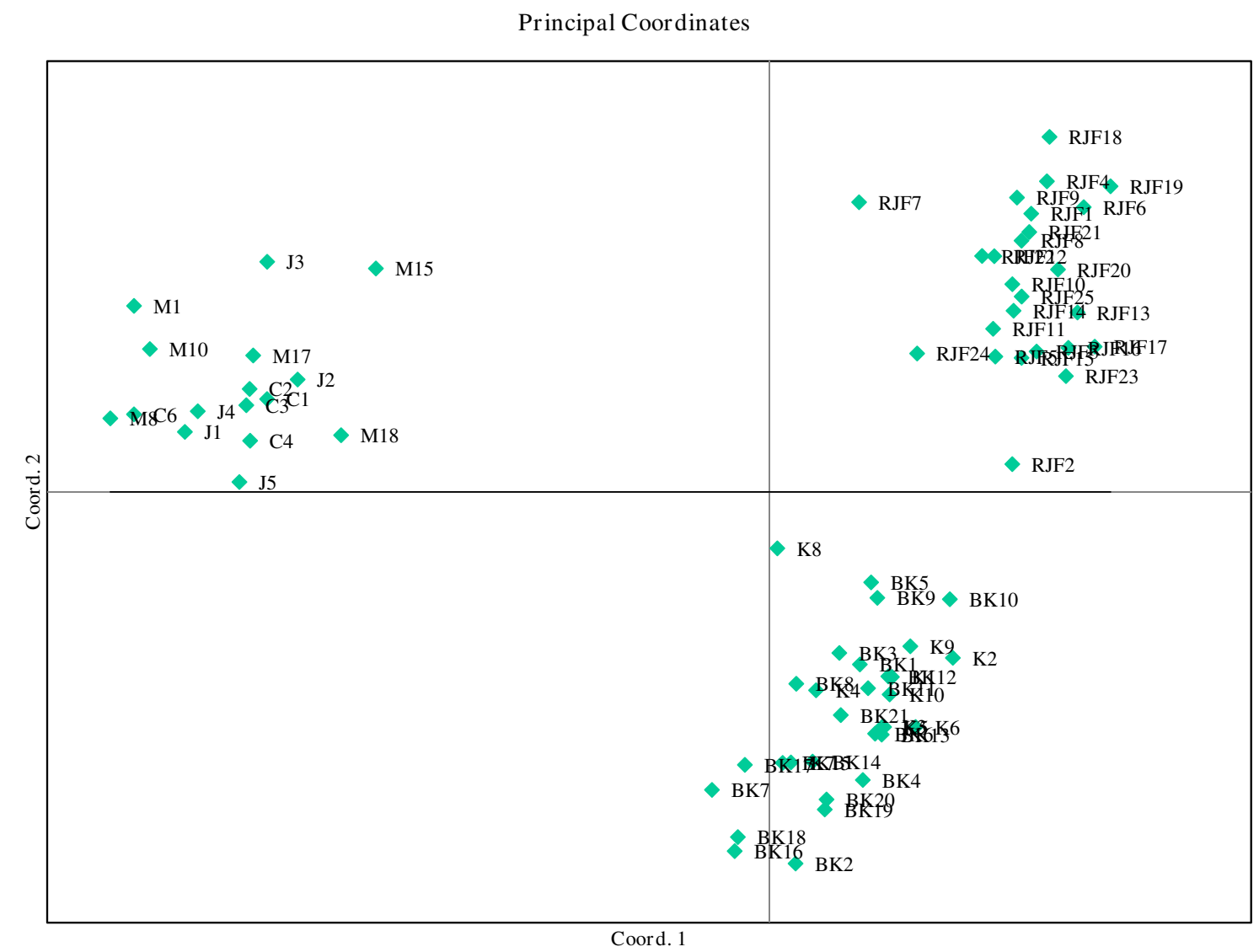

Figure 2

Principal component analysis based on genetic distances of Indian chicken. The clear clustering of all domestic chicken to a single quadrate (upper left) indicates absence of hybridization between domestic chicken and RJFs.

To understand the demographic history of the two populations, we obtained pairwise mismatch distribution estimates. In an expanding population, mismatch distribution is expected to be a bell shaped smooth curve, whereas population at constant growth shows raggedness. In the present study, observed mismatch distribution was bell-shaped for 56 Indian birds of G. g. murghi (Fig. 3). However, appearance of multiple peaks suggested a population subdivision, which was more prominent in $G . g$. domesticus than in G. g. murghi. This also suggests homogenous population of G. g. murghi, again supporting our notion that inbreeding is more common in RJF than in domestic birds. Harpending's raggedness index was lower in G. g. murghi (0.001515) than in G. g. domesticus (0.0149), but was significant $(P<0.05)$ in both the populations reiterating population expansion.

\section{Phylogeny and median-joining network profiles of Indian birds in comparison to global populations}

In the present study we also compared the D-loop sequence of 76 birds with the corresponding sequences (approximately 400-440 bp) of 779 birds from NCBI GenBank to get insight into phylodemographic status of G. g. murghi and G. g. domesticus (India). Of the 855 sequences, 117 were from RJFs, 714 were from domestic chicken and the rest belonged to other species of Gallus. These 855 birds were classified into 13 groups based on geographical location and species/sub-species status as shown in Table 3. We included Japanese quail, Coturnix japonica as an outgroup whenever necessary.

All the 855 sequences resulted in 117 segregating sites and 146 haplotypes with a haplotype diversity of 0.940 and an average nucleotide diversity of 0.020 . The NJ tree generated from the haplotype data revealed two distinct G. gallus clusters, one consisting of the G. g. bankiva group, and the remaining cluster containing all the other groups namely, G. g. spadiceus, G. g. gallus, G. g. murghi, G. g. jabouillei and G. g. domesticus. Irrespective of the geographic distribution and sub-species status, more than $95 \%$ of the birds clustered within this single largest group (Fig. 4 - see discussion). This result is consistent with the 


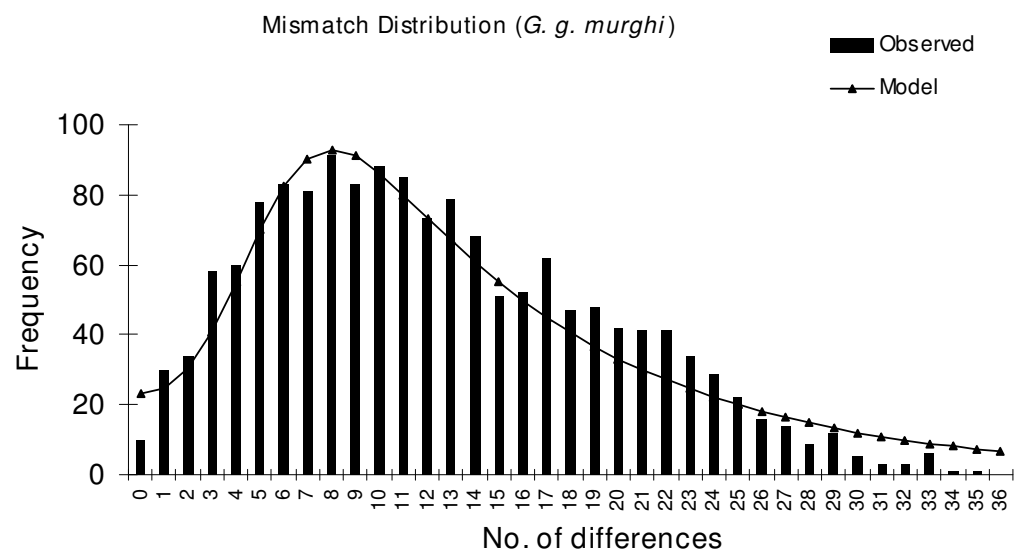

Mismatch Distribution (G. g. gallus)

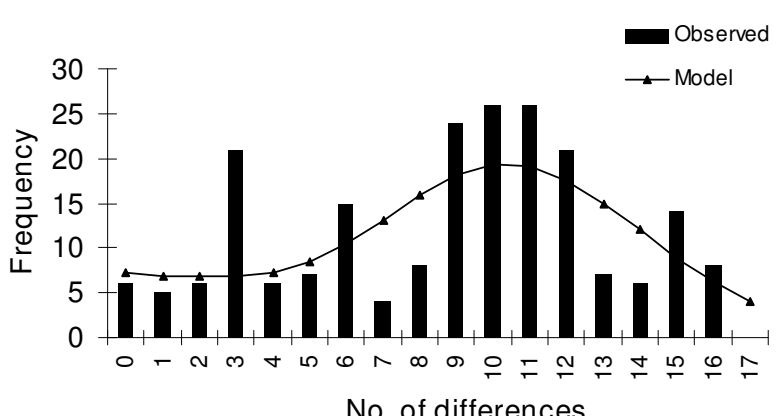

Mismatch Distribution (G. g. domesticus)

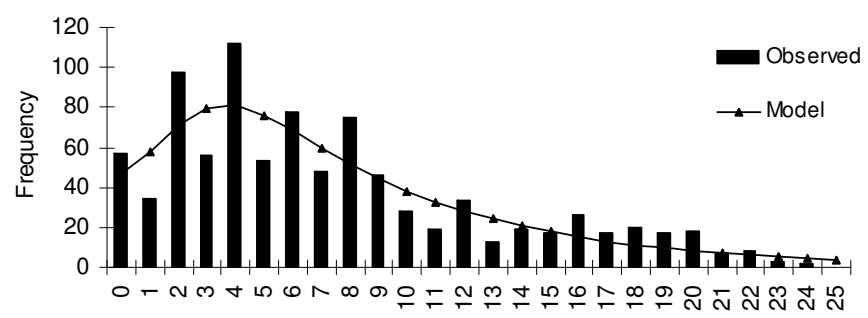

No. of differences

Figure 3

Mismatch distribution of G. g. murghi, G. g. domesticus (India) and G. g. gallus. Observed and model frequencies are indicated. A bell shaped curve characteristic of expanding population is seen for $G$. g. murghi.

neighbor-joining tree of all 855 birds (Additional file 2), where we observed a single clade for all domestic and RJF birds. However, in contrast to Fumihito et al.'s work [5], we observed a clear segregation of a clade containing G. varius, G. lafayettei and G. sonneratii from all RJF/domestic bird combination, which reassures us about the absence of the hybridization. Such a topology was also evident from the haplotype-based tree (Fig. 4)

To obtain further insight into the haplotype relationships, we constructed a median-joining network using 146 haplotypes. In the haplotype network, most of the G. g. gallus formed individual nodes (e.g. H_1, H_2, H_78, H_79) and clustered independently, while many G. g. murghi haplotypes (H_86 to H_99 and H_102 to H_123) grouped around a major cluster (H_112) having 16 birds, giving rise to a star like phylogeny (Fig. 5). The largest haplotype H_3 (with 127 birds) confined mostly to Chinese G. g. domesticus birds without any representation of jungle fowls. Thirty nine birds of G. g. spadiceus belonging to 9 haplotypes did not have any representation from $G$. g. murghi birds. The second largest haplotype (H_61 with 102 birds) shared only a single individual of G. g. gallus and many G. g. domesticus from China, India, Japan and Indonesia. Forty-three G. g. domesticus of India (19 haplotypes) were distributed throughout the network. These haplotypes were connected with G. g. gallus, G. g. murghi and G. g. spadiceus. The haplotype H_63 contained G. g. domesticus (India) birds reported in the present study as well as from an earlier study [8]. Interestingly, majority of the Indian G. g. domesticus haplotypes shared the birds from the three major G. gallus groups belonging to G. $g$. spadiceus (H_58, H_61), G. g. gallus (H_59, H_61), and also G. g. murghi (H_6). It is very likely that G. g. spadiceus has also contributed to the domestic chicken. Apart from Indian RJF, G. g. murghi haplotype H_6 also contained 5 Chinese, 1 Iranian and 1 Japanese domestic chicken. The distribution of Indian domestic chicken into different haplotypes could imply multiple origins of Indian domestic chicken breeds. 
Table 3: Standard diversity indices and mismatch distribution analyses obtained from d-loop sequence of 855 birds belonging to 13 populations. Coturnix japonica that was used as an outgroup is not included.

\begin{tabular}{|c|c|c|c|c|c|c|c|c|c|c|c|c|c|}
\hline \multirow[t]{2}{*}{ Group $\rightarrow$} & \multicolumn{5}{|c|}{ G. gallus domesticus (Domestic chicken) } & \multicolumn{4}{|c|}{ G. gallus (RJF) } & \multicolumn{4}{|c|}{ Other species of Gallus } \\
\hline & India & Indonesia & Japan & Misc.* & China & murghi & gallus & spadiceus & Bankiva & jabouillei & $\begin{array}{c}\text { G. } \\
\text { Varius }\end{array}$ & $\begin{array}{c}G . \\
\text { lafayettei }\end{array}$ & $\begin{array}{c}\text { G. } \\
\text { sonneratii }\end{array}$ \\
\hline Sample size & 43 & 12 & 104 & 4 & 551 & 56 & 21 & 41 & 6 & 3 & 4 & 3 & 6 \\
\hline Haplotypes & 23 & 6 & 26 & - & 82 & 42 & 15 & 12 & 6 & - & - & - & 5 \\
\hline $\begin{array}{l}\text { Haplotype diversity } \\
(\mathrm{Hd})\end{array}$ & 0.932 & 0.836 & 0.925 & - & 0.934 & 0.948 & 0.971 & 0.789 & 1.000 & - & - & - & 0.933 \\
\hline Sum of square freqs. & 0.023 & 0.083 & 0.010 & 0 & 0.002 & 0.018 & 0.048 & 0.024 & 0.167 & 0 & 0.250 & 0.333 & 0.167 \\
\hline $\begin{array}{l}\text { Number of observed } \\
\text { transitions }\end{array}$ & 30 & 16 & 30 & 17 & 49 & 45 & 31 & 23 & 8 & 14 & 7 & 4 & 33 \\
\hline $\begin{array}{l}\text { Number of observed } \\
\text { transversions }\end{array}$ & 20 & 0 & 3 & 0 & 9 & 47 & 3 & 4 & 0 & I & 3 & 1 & 2 \\
\hline $\begin{array}{l}\text { Number of } \\
\text { substitutions }\end{array}$ & 50 & 16 & 33 & 17 & 58 & 92 & 34 & 27 & 8 & 15 & 10 & 5 & 35 \\
\hline $\begin{array}{l}\text { Number of } \\
\text { polymorphic sites }\end{array}$ & 55 & 16 & 37 & 17 & 55 & 113 & 36 & 29 & 10 & 15 & 75 & 5 & 39 \\
\hline $\begin{array}{l}\text { Nucleotide diversity } \\
\text { Standard deviation }( \pm)\end{array}$ & $\begin{array}{l}0.018 \\
0.009\end{array}$ & $\begin{array}{l}0.015 \\
0.008\end{array}$ & $\begin{array}{l}0.021 \\
0.011\end{array}$ & $\begin{array}{l}0.024 \\
0.016\end{array}$ & $\begin{array}{l}0.018 \\
0.009\end{array}$ & $\begin{array}{l}0.029 \\
0.015\end{array}$ & $\begin{array}{l}0.022 \\
0.011\end{array}$ & $\begin{array}{l}0.023 \\
0.011\end{array}$ & $\begin{array}{l}0.012 \\
0.008\end{array}$ & $\begin{array}{l}0.025 \\
0.019\end{array}$ & $\begin{array}{l}0.082 \\
0.054\end{array}$ & $\begin{array}{l}0.007 \\
0.006\end{array}$ & $\begin{array}{l}0.034 \\
0.020\end{array}$ \\
\hline $\begin{array}{l}\text { Mismatch observed } \\
\text { mean }\end{array}$ & 7.409 & 6.000 & 8.670 & 9.500 & 7.354 & 12.436 & 8.800 & 9.229 & 5.000 & 10.000 & 38.000 & 3.333 & 16.000 \\
\hline $\begin{array}{l}\text { Harpending's } \\
\text { Raggedness index }\end{array}$ & 0.021 & 0.236 & 0.012 & 0.167 & 0.009 & 0.001 & 0.029 & 0.136 & & & 0.750 & 1.000 & 0.289 \\
\hline $\begin{array}{l}P \text { (Sim. Rag. }>=\text { Obs. } \\
\text { Rag.) }\end{array}$ & 0.310 & 0.000 & 0.230 & 0.960 & 0.310 & 1.000 & 0.300 & 0.000 & & & 0.120 & 0.860 & 0.160 \\
\hline Tajima's D & -1.406 & 0.571 & 0.835 & 0.250 & -0.148 & -1.923 & -0.352 & 1.518 & 0.947 & 0 & -0.222 & 0 & -0.357 \\
\hline $\mathrm{P}(\mathrm{D}$ random $<\mathrm{D}$ obs $)$ & 0.075 & -0.293 & -0.204 & -0.321 & 0.470 & 0.015 & 0.383 & -0.073 & -0.204 & 0 & 0.540 & 0 & 0.420 \\
\hline Fs & -24.995 & -7.215 & -24.627 & 0.273 & NC & $-24.40 \mathrm{I}$ & -14.732 & -24.738 & -2.160 & 1.139 & 1.798 & -0.077 & -0.284 \\
\hline $\begin{array}{l}\text { Prob(sim_Fs }<= \\
\text { obs_Fs) }\end{array}$ & 0 & 0.001 & 0 & 0.319 & - & 0 & 0 & 0 & 0.049 & 0.46 & 0.496 & 0.239 & 0.233 \\
\hline
\end{tabular}

* Misc. represents birds from Iran, UK and Vietnam. NC - not calculated.

The sequenced regions of D-loop were well conserved in most of the birds. The $62 \mathrm{bp}$ insertion element found in G. sonneratii was the only indel of considerable size present in the whole sequence. The salient mutation observed in G. g. murghi was the presence of 'T' in most of the birds (54 out of 56 i.e. $96.4 \%$ ) (Fig. 4) that was present in only $33.3 \%$ of G. g. gallus, $24.4 \%$ of G. g. spadiceus and $13.1 \%$ of all the G. g. domesticus birds. Only three Indian G. g. domesticus $(6.9 \%)$ had ' $\mathrm{T}$ ' at this position. This position corresponds to the nucleotide number 360 (where there is ' $\mathrm{C}$ ') in the complete mitochondrial genome sequence of G. gallus (Acc. No. NC 001323) available in GenBank. Across the portion of the sequenced mitochondrial genome we observed that transition to transversion ratio was lower in case of G. g. murghi $(45 / 47=0.99)$ than in G. g. gallus $(31 / 2=15.5)$ or G. g. spadiceus $(23 / 4=5.75$ - Table 3).

Mismatch distribution analyses carried out under sudden expansion model showed that mean pairwise differences were highest in G. g. murghi among G. gallus sub-species. However, another species of Gallus, G. sonneratii had the highest mean pairwise differences (Table 3). Both Tajima's D and Fu's Fs were significantly $(P<0.05)$ negative in G. g. murghi, suggesting the departure from neutrality (Table 3). Tajima's D was significant only in G. $g$. spadiceus and G. g. murghi. Fu's $\mathrm{F}_{\mathrm{S}^{\prime}}$ a better indicator for estimating the departures from neutral theory, showed a significant negative value $\left(P\right.$ of $\operatorname{simF}_{\mathrm{S}}<=\mathrm{obsF}_{\mathrm{S}}$ is $<0.01$ ) for G. g. murghi and G. g. domesticus (Indonesia). Nucleotide diversity was also high (0.030) in case of G. $g$. murghi (except for G. sonneratii) amongst all the groups studied (Table 3).

The $\mathrm{F}_{\mathrm{ST}}$ values showed a very high differentiation between the out group C. japonica and the other 13 populations, with a value above 0.9. Most of the pairwise $\mathrm{F}_{\mathrm{ST}}$ values were significant with a $P$ value $<0.05 . \mathrm{F}_{\mathrm{ST}}$ value $[20]$ based NJ tree showed the divergence of G. g. murghi from G. $g$. gallus, G. g. spadiceus and G. g. domesticus (Additional file $3)$. AMOVA calculations showed that the majority of variation found within G. gallus subspecies was between the domestic and jungle fowl populations (76\%), while 'among the group' variation was $7 \%$ with an overall $\mathrm{F}_{\mathrm{ST}}$ value of $0.234(P=0)$.

\section{Discussion}

In the present study we attempted to understand the contribution of Indian red jungle fowl, G. g. murghi to the domestication event. As of now, no sequence information is available from this group of birds which, in all likelihood, was contributor of one of the earliest known chicken domestication event, i.e. in Mohanjo-Daro. We studied Indian birds belonging to two species of Gallus 


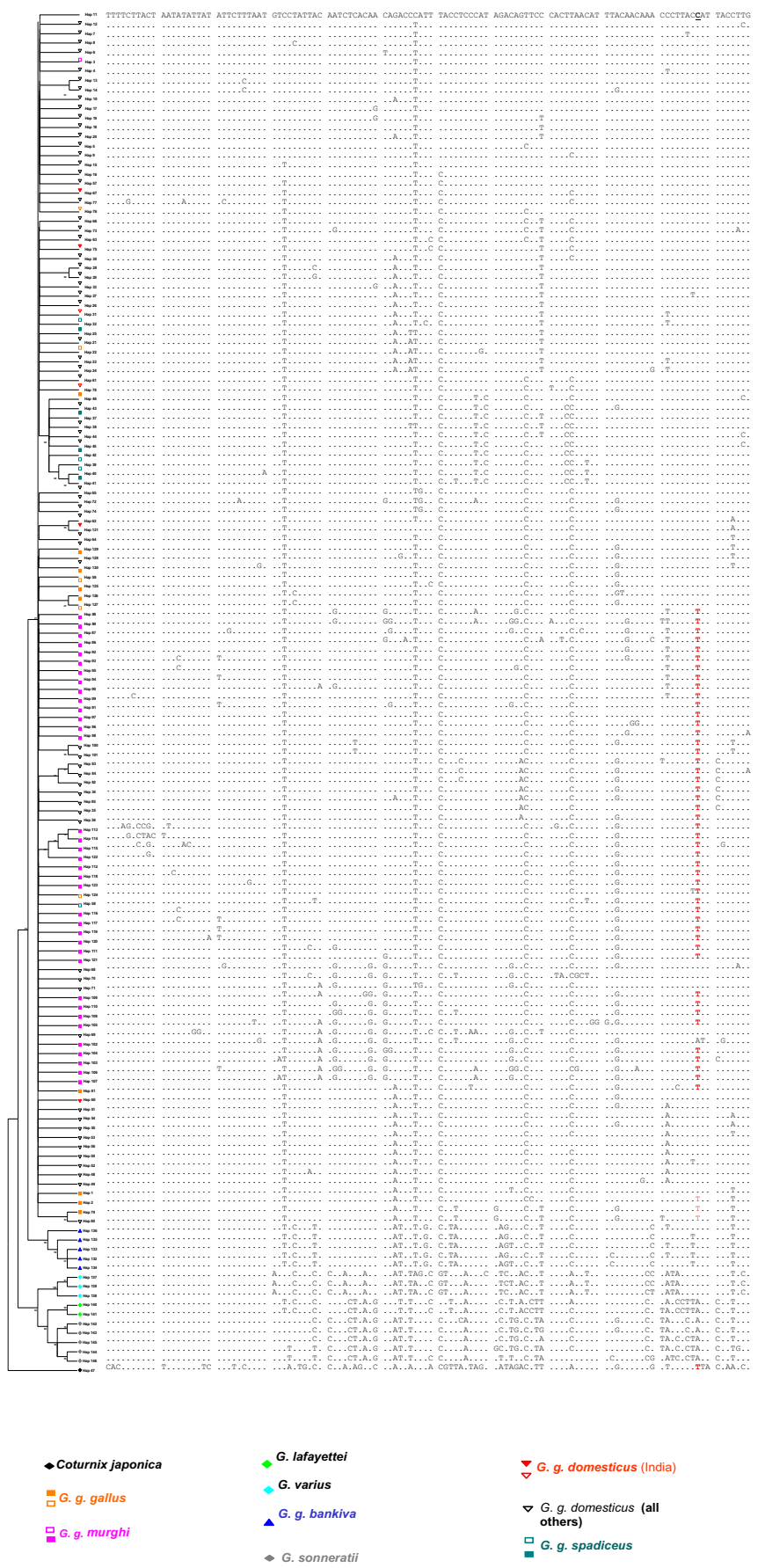

\section{Figure 4}

A NJ haplotype tree obtained by $50 \%$ consensus rule using 117 variable sites within the sequenced portion of the D-loop, with their corresponding haplotypes generated from the 146 haplotypes of $\mathbf{8 5 5}$ birds. Different haplotypes are color-coded based on the group they belong to (See methods section for grouping details) as indicated. Filled structures indicate haplotypes consisting of all birds of the same group (e.g. Indian RJF-pink colored), while open structures indicate the presence of at least one bird of a specified/color-coded group that also contains birds belonging to other groups (e.g. Indian RJF containing domestic birds). Different sub-species of $G$. gallus form only two clusters, one of $G$. g. bankiva and others containing all other sub-species. The cluster of $G$. gallus sub-species, however also contained another species of Gallus, namely $G$. lafayettei. Identical sequences are shown as dots in comparison with $\mathrm{H}$ _II. A specific mutation found in $96 \%$ of $G$. g. murghi is shown in bold and red color and the corresponding nucleotide is underlined in $\mathrm{H}$ II. This position corresponds to the nucleotide number 360 (where there is ' $\mathrm{C}$ ') in the complete mitochondrial genome sequence of $G$. gallus (Acc. No. $\mathrm{NC} \mathrm{001323)}$ ). The color-coding used is represented below the figure. 


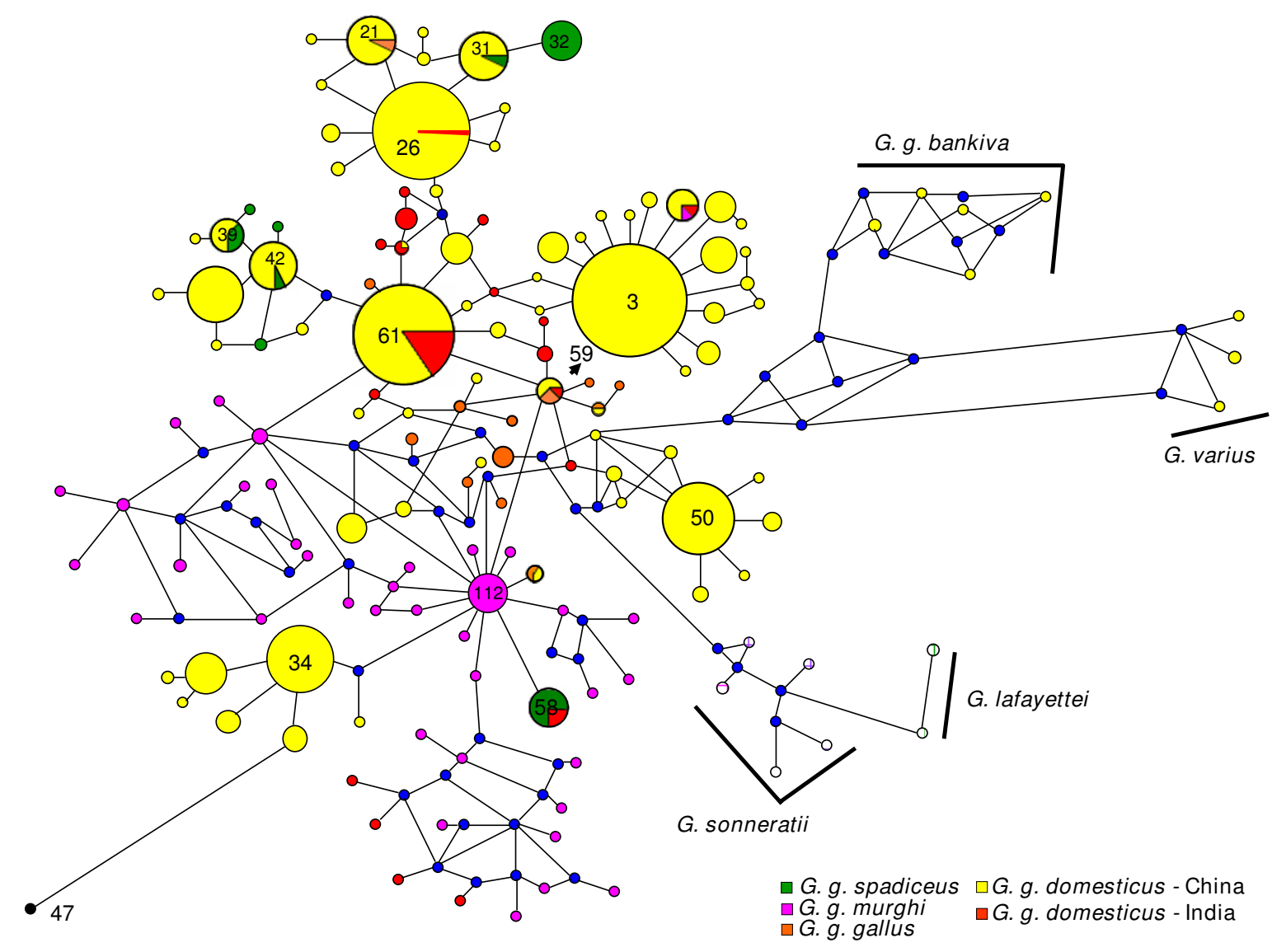

Figure 5

Median-joining haplotype network of 855 birds belonging to I 46 haplotypes. Various haplotypes of chicken species/ sub-species are represented in different colored circles. The size of the circles is proportional to the haplotype frequency. Some of the important haplotype numbers are indicated. The median vectors that represent hypothetical intermediates or unsampled haplotypes, are shown in blue circles. The data indicate formation of a star-like phylogeny of G. g. murghi around H_I I2. Black circle (H_47) indicates $C$. japonica. Other Gallus species are indicated by their names.

and compared them with the worldwide bird populations. Since microsatellite markers and the D-loop sequence of mitochondrial DNA have a high mutation rates, they provide information about recent evolutionary history as compared to slow mutating genes that provide data about ancient history [21]. To reconstruct the recent past, we used both these marker systems and also addressed the issue of genetic purity of wild birds.

From the mtDNA analysis, we observed that a group of $G$. g. domesticus birds had the G. g. murghi haplotype (H_6), while a few others shared haplotypes with G. g. gallus (H_21, H_59, H_61 etc.) and with G. g. spadiceus (H_39, H_42, H_58 etc.). This is also true for Indian chicken that have originated by independent domestication from G. $g$. murghi as well as possibly from other G. g. subspecies. Interestingly, sharing of different haplotypes by Indian domestic chicken clarify that the present day Asiatic chicken might have originated from different progenitors by multiple domestication events and such multi-origin breeds could still be observed in a single geographical location. This is consistent with the observation of Oka et al. [22], who showed that the present day native Japanese chicken are having multiple origin.

A model explaining the origin of Indian domestic bird by multiple domestications is depicted schematically in Fig. 6. Sharing of haplotypes, as indicated in this model, suggests multiple origins to Indian domestic chicken. Independent domestications have also been reported for cattle [23], pig [24] suggesting that such events are not rare. However, all the birds except G. g. bankiva form a single cluster suggesting a common ancestor long back in history for these birds including jungle fowls and domestic birds. The separation of G. g. bankiva from the main cluster of birds indicates the possibility of a speciation event. 

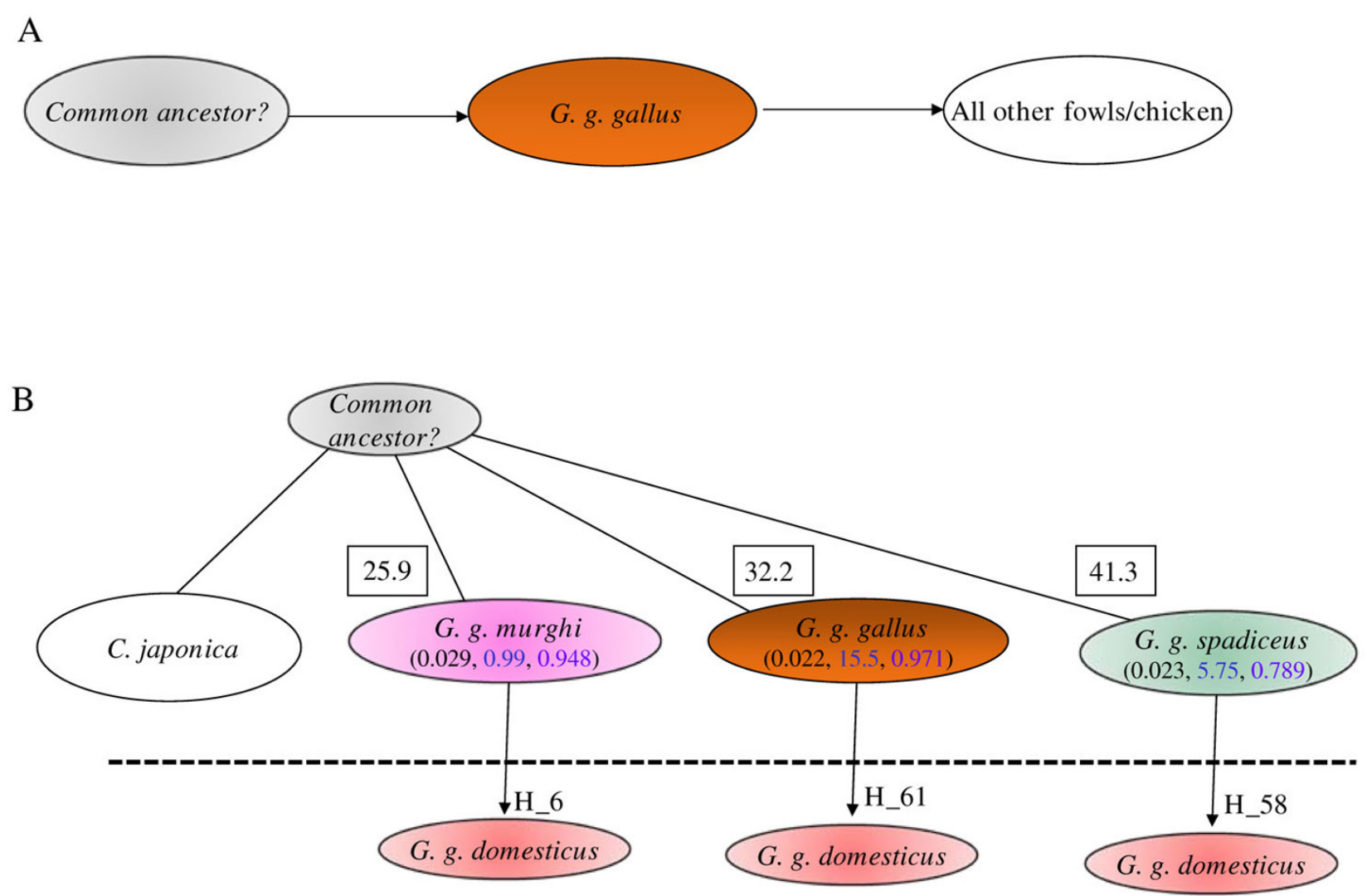

Figure 6

Comparison of (A) single domestication against (B) multiple domestication hypothesis. The present study supports the hypothesis B for origin of domestic chicken. The numbers in parenthesis indicate the nucleotide diversity ( $\mathrm{p}$-black), transition-to-transversion ratio (Ts/Tv-blue) and haplotype diversity (Hd-violet), respectively. The number inside the square indicates average number of mutational events of each group from the outgroup, $C$. japonica. The sharing of the haplotypes (as exemplified by $\mathrm{H}$ number) indicates the multiple origin of the domestic chicken from different jungle fowls. Low mutational distance, low Ts/Tv ratio and high nucleotide diversity indicate the ancient nature of Indian RJF, G. g. murghi. The dashed line separates domestic chicken (below the line) from other birds.

The multilocus microsatellite data as well as the D-loop sequence of Indian chicken showed departure from neutrality as indicated by significant negative value of Tajima's D and Fu's Fs for G. g. murghi suggesting the possible population expansion of Indian birds. These results are also consistent with mismatch distribution analyses and significant value for Harpending's raggedness index (Table 3). Taken together with the genetic diversity analyses, we surmise that G. g. murghi and G. g. domesticus (India) must have undergone population expansion. It is believed that population expansion follows a domestication event. This fact holds true even in case of chicken, where we did observe population expansion, as did previous studies.

Our analyses revealed that the sampled Indian birds are relatively pure with very rare hybridization between $G . g$. murghi and G. g. domesticus (India). Nishibori et al. [11] suggested the hybridization of RJF with domestic and grey jungle fowl. In the present study of Indian birds, we did not come across noticeable hybridization at least in the recent past, as indicated by very low $\mathrm{F}_{\mathrm{ST}}$ values for mtDNA (Table 2) and microsatellite markers and also a clear separation of RJF clades from domestic chicken in microsatellite based phylogeny. All these results indicate the genetic integrity of the G. g. murghi.

In the present study, we observed predominant occurrence of a characteristic ' $T$ ' nucleotide in $96.4 \%$ of $G . g$. murghi birds that is absent in most of the Indian domestic chicken further supporting the occurrence of negligible hybridization between G. g. murghi and G. g. domesticus (India). All the sampled G. sonneratii had 'A' nucleotide in this position. If the frequent hybridization is occurring then it is expected that at least a few of G. g. murghi to have 
'A' at this position. Since we found only one RJF with 'A' at this site, and also due to clear separation of the clades, it is unlikely that G. g. murghi and G. sonneratii hybridize in the wild contrary to the observations made by Nishibori et al. [11] who suggested the possible hybridization between the RJF and GJF. Such contrasting observations may be due to the limited number of samples (3 RJF and 3 GF) used by Nisibori et al. [11]. Taken together with the Fumihito et. al.'s [6,7] and Liu et al.'s [8] observations our results prompted us to question the sub-species status for G. g. gallus, G. g. spadiceus, G. g. murghi and G. g. domesticus. In the light of these findings, we recommend that $G$. gallus should be classified as G. g. gallus that should include all RJFs and G. g. domesticus birds. At the same time, after confirmation of reproductive isolation, $G$. $g$. bankiva could be placed into a separate species, Gallus bankiva.

\section{Conclusion}

For the first time by analyzing hitherto unreported samples of G. g. murghi and also including the G. g. domesticus (India), we confirm that the domestication of chicken has occurred independently from G. g. murghi. We also provide evidence that there is little genetic exchange between G. g. murghi and G. g. domesticus (India) and minimal hybridization between G. sonneratii and G. g. murghi. Comparison of Indian RJF and domestic bird to that of world population also supports the previous studies of obsoleteness of the sub-species status given to RJFs and domestic chicken.

\section{Methods}

\section{Samples, DNA isolation}

Blood samples were collected from 3 geographically isolated populations of G. g. murghi i.e. Morni Hills ('M-RJF',

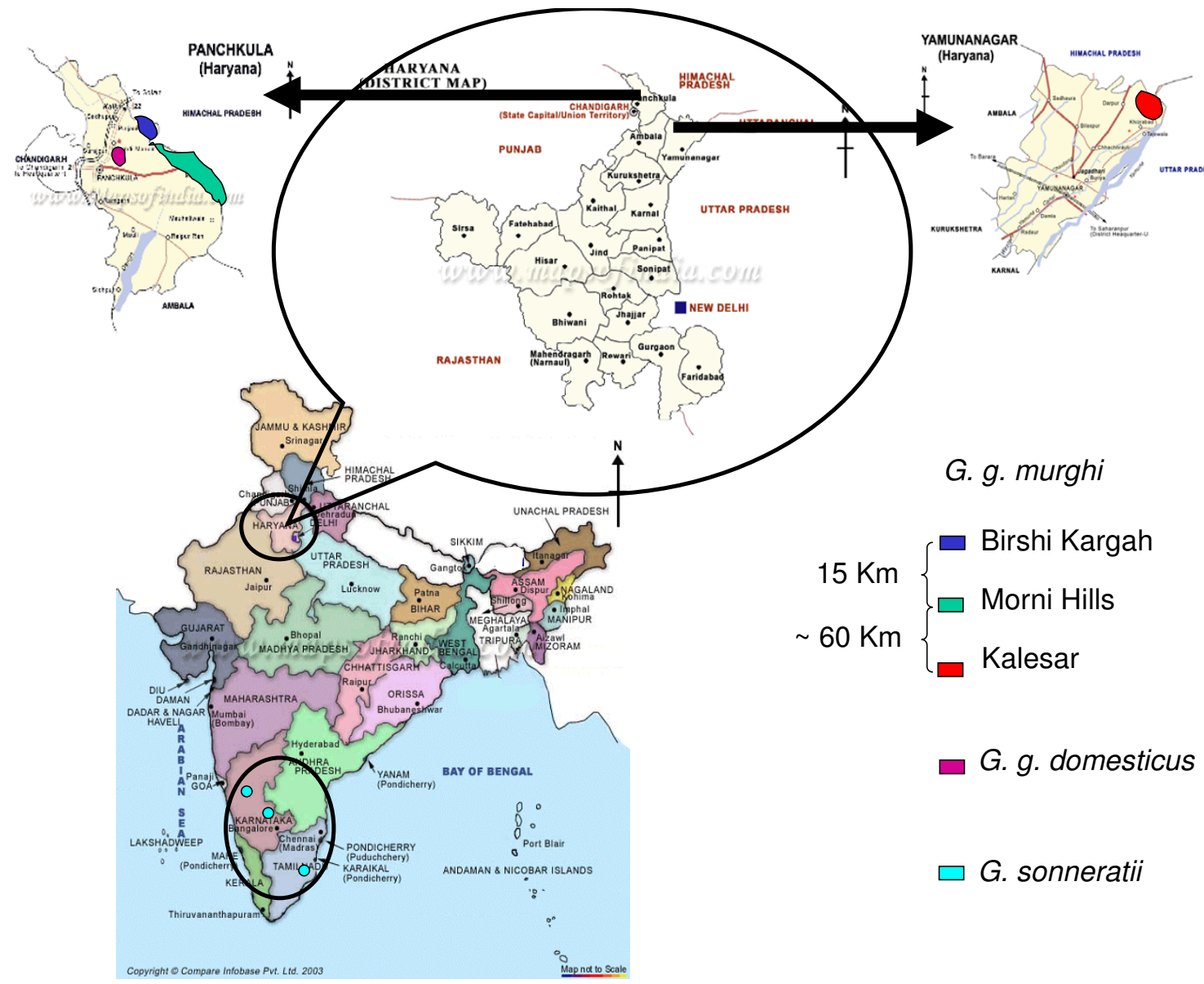

Figure 7

Map of India showing the sampling locations. RJFs were collected from two districts, while domestic birds were from the same district of Haryana state in north-west India. Grey jungle fowls were from south India. Distances between the villages are shown in kilometers. The places from where the samples were collected are shown in colored circles. $G$. sonneratii was collected from the south Indian states of Karnataka and Tamilnadu. 
$\mathrm{n}=25$ ), Kalesar Forest ('K-RJF', n = 10) and Birshi Kargah Forest ('B-RJF', $\mathrm{n}=21$ ) of Haryana State of India (Fig. 7), 3 populations of G. g. domesticus birds i.e. Chicken ('C', $\mathrm{n}$ = 5), Jodhpur ('J', n = 5) and Mirpur Bakshiwala ('M', n = 6) villages of Haryana. Grey Jungle fowl (G. sonneratii) blood samples $(n=4)$ were collected from different Zoological Parks of South India and were considered as a single population. Except for the G. g. domesticus birds, which were collected from specific villages, all the other birds were captive bred from the founder-lines that were obtained from the specified village. The 76 birds were considered as belonging to 7 populations (3 RJF, 3 domestic and a single population of GJF).

About $0.5 \mathrm{ml}$ of blood was collected from the wing vein of live birds into vials containing $5 \mathrm{mM}$ EDTA and genomic DNA was isolated as per standard protocols [25].

\section{PCR amplification of microsatellite loci}

The microsatellite loci used in the study, the primer details and PCR conditions are available in Table 1. The PCR products were separated on 3.5\% Metaphor agarose gel along with pUC/MspI digest (MBI Fermentas) ladder. For GeneScan analysis, the PCR products generated using fluorescent dUTPs were dissolved in $2 \mu$ l of formamide gel loading buffer with $0.3 \mu \mathrm{l}$ of ROX $-500^{\mathrm{TM}}$ GeneScan ruler (Perkin Elmer) and separated on a 5\% polyacrylamide-7 M Urea gel.

\section{PCR amplification and Sequencing of D-loop of mitochondrial DNA}

The D-loop hypervariable region was PCR amplified using primers described elsewhere [7]. The sequencing was carried out on both the strands. We also used an internal primer (5'GTGGAATATAGGTTAATGCC 3') to obtain the sequence information from 5' region without any ambiguity. $50 \mathrm{ng}$ PCR product was used in a sequencing reaction that contained $8 \mu$ l of Ready reaction mix (BDT v 3.0, Applied Biosystems, Foster City, CA) and 5 picomoles of primer. The sequencing was carried out in ABI Prism 3100 Genetic Analyzer (Applied Biosystems).

\section{Data analysis}

Microsatellite Data

The individuals were genotyped based on allele size data. Allele frequency and heterozygosity were calculated using GenAlEx [26]. F-statistics were used as a measure of diversity within and between populations and were estimated using GenAlEx. For PCA, genetic distance was calculated from the allele data and the genetic distance was plotted as PCA using GenAlEx. Population history parameters were calculated using Arlequin [27]. The microsatellite allele frequency data from different populations was bootstrapped using seqboot of Phylip and the output file was used for construction of maximum likelihood (ML) tree using Phylip 'contml' program. For distance based NJ tree, the genetic distance was calculated using GenAlEx program and the resulting distance matrix was used to construct NJ tree with Kimura-2-parameter (K2P) option in MEGA.

\section{Mitochondrial DNA}

Mitochondrial D-loop sequences of 779 Jungle Fowls and G. g. domesticus birds as well as other species of Gallus were obtained from GenBank [28] (available as Additional file 4 ). The sequences of 855 birds, including the 76 samples sequenced in the present study were aligned using ClustalX program [29], manually edited using GeneDoc [30] and the region conserved in all the birds was used for analysis. With gaps there were a total of 482 bp sequence, with highest number of nucleotides (460-462) coming from the $G$. sonneratii and approximately 400 bp from RJFs. Similar to previous phylogenetic studies, we used Coturnix japonica as an outgroup in our study. The phylogenetic trees were constructed using Phylip 3.5 [31] or MEGA [32]. The best fit model was selected using the program MODELTEST [33] as implemented in HyPhy [34]. The alpha value obtained from best-fit model was used for gamma correction in haplotype NJ tree, which was constructed using Tajima and Nei's model in MEGA3. Haplotype data was obtained using DnaSP [35] and was used to construct haplotype network using Network program [36]. Default parameters were used for obtaining the median joining network tree. Population genetic structure was measured using AMOVA as implemented in Arlequin with 1000 permutations. Tajima's D [37], Fu's Fs [38] and other population genetics parameters were also calculated using Arlequin for which the significance was tested after 1000 simulation steps [27]. For such analyses, populations were defined depending on the data being analyzed - e.g. in case of Indian chicken, as $2 \mathrm{G}-2$ populations viz. G. g. domesticus and G. g. murghi, 6G-3 sub populations each based on the sampling location in both $G$. $g$. domesticus (C, J, M) and G. g. murghi populations (M-RJF, B-RJF, K-RJF) or 7G (6G and G. sonneratii). Such a classification was carried out to study the population genetic structure within the subdivided populations. Whenever necessary, as in case of subdivided populations, realignment of the sequence was carried out using clustalX.

We investigated the demographic profiles of chicken populations based on coalescence theory and analyzed pairwise mismatch distribution to confirm the population expansion [39], using Arlequin. The parameter of demographic expansion $\tau$ was estimated with a generalized nonlinear least squares approach and approximate confidence intervals were obtained with 1000 parametric bootstrap replicates. The goodness-of-fit of the observed data to a simulated model of expansion was tested with the sum of squared deviations and Harpending's raggedness 
index was estimated [40]. For bootstrap phylogenetic NJ tree, the aligned mtDNA sequence was run in MEGA with 1000 replicates with a $50 \%$ cutoff option.

\section{Authors' contributions}

RDJ carried out sample collection, MM did the PCR and sequencing and contributed to analyses, SK carried out the computational and phylogenetic analyses and prepared the manuscript, JN conceived the study, participated in its design and coordination and revision of the manuscript.

\section{Additional material}

\section{Additional file 1}

Table S1. GenAlex file showing the Nei's genetic distance, HWE and allele frequencies.

Click here for file

[http://www.biomedcentral.com/content/supplementary/1471-

2148-8-174-S1.xls]

\section{Additional file 2}

Fig. S1. A bootstraped NJ tree of all 855 birds obtained using MEGA. The value indicates the bootstrap support. The names of individual birds has been modified, hence may not exactly correlate with Table S2.

Click here for file

[http://www.biomedcentral.com/content/supplementary/14712148-8-174-S2.doc]

\section{Additional file 3}

Fig. S2. $F_{S T}$ value based NJ tree showing the divergence of $\mathrm{G}$. g. murghi from G. g. gallus, G. g. spadiceus and G. g. domesticus. Clade I contains all RJFs and domestic chicken subgroups.

Click here for file

[http://www.biomedcentral.com/content/supplementary/14712148-8-174-S3.pdf]

\section{Additional file 4}

Table S2. Details of 855 birds used in the present study.

Click here for file

[http://www.biomedcentral.com/content/supplementary/14712148-8-174-S4.doc]

\section{Acknowledgements}

We acknowledge the financial support received from the Department of Forests, Govt. of Haryana, India. We thank Mr. JPL Srivastava, Principal Chief Conservator of Forests, Govt. of Haryana for his support throughout the research.

\section{References}

I. Zeuner FE: A History of Domesticated Animals. Harper and Row, New York; 1963.

2. West B, Zhou B-X: Did chicken go north? New evidence for domestication. J Archaeol Sci 1988, 15:515-533.

3. Stevens L: Genetic and evolution of the domestic fowl. New York, Cambridge University Press; 1991.

4. Peterson AT, Brisbin IL Jr: Genetic endangerment of wild red jungle fowl (Gallus gallus)? Bird Conservation International 1999, 9:387-394.
5. Moiseyeva IG, Romanov MN, Nikiforov AA, Sevastyanova AA, Semyenova SK: Evolutionary relationships of Red Jungle Fowl and chicken breeds. Genet Sel Evol 2003, 35(4):403-423.

6. Fumihito A, Miyake T, Takada M, Shingu R, Endo T, Gojobori T, Kondo N, Ohno S: Monophyletic origin and unique dispersal patterns of domestic fowls. Proc Natl Acad Sci U S A 1996, 93(I 3):6792-6795.

7. Fumihito A, Miyake T, Sumi S, Takada M, Ohno S, Kondo N: One subspecies of the red junglefowl (Gallus gallus gallus) suffices as the matriarchic ancestor of all domestic breeds. Proc Natl Acad Sci U S A 1994, 9 I(26): I 2505-12509.

8. Liu YP, Wu GS, Yao YG, Miao YW, Luikart G, Baig M, Beja-Pereira A Ding ZL, Palanichamy MG, Zhang YP: Multiple maternal origins of chickens: out of the Asian jungles. Mol Phylogenet Evol 2006, 38(I):12-19.

9. Niu D, Fu Y, Luo J, Ruan H, Yu XP, Chen G, Zhang YP: The origin and genetic diversity of Chinese native chicken breeds. Biochem Genet 2002, 40(5-6): 163-174.

10. Brisbin IL, Peterson AT, Okimoto R, Amato RG: Characterization of the genetic status of populations of red jungle fowl. J Bombay Natural History Society 2002, 99:21 7-223.

II. Nishibori M, Shimogiri T, Hayashi T, Yasue H: Molecular evidence for hybridization of species in the genus Gallus except for Gallus varius. Anim Genet 2005, 36(5):367-375.

12. Harpending HC, Batzer MA, Gurven M, Jorde LB, Rogers AR, Sherry ST: Genetic traces of ancient demography. Proc Natl Acad Sci U S A 1998, 95(4): 1961-1967.

13. Berlin S, Ellegren H: Evolutionary genetics. Clonal inheritance of avian mitochondrial DNA. Nature 200I, 4I3(685I):37-38.

14. Savolainen P, Zhang YP, Luo J, Lundeberg J, Leitner T: Genetic evidence for an East Asian origin of domestic dogs. Science 2002, 298(5598): $1610-1613$

15. Storey AA, Ramirez JM, Quiroz D, Burley DV, Addison DJ, Walter R, Anderson AJ, Hunt TL, Athens SS, Huynen L, Matisoo-Smith EA: Radiocarbon and DNA evidence for a pre-Columbian introduction of Polynesian chickens to Chile. Proc Natl Acad Sci U S A 2007, 104(25): 10335-10339.

16. Schlotterer C: The evolution of molecular markers--just a matter of fashion? Nat Rev Genet 2004, 5(I):63-69.

17. Hillel J, Groenen MA, Tixier-Boichard M, Korol AB, David L, Kirzhner VM, Burke T, Barre-Dirie A, Crooijmans RP, Elo K, Feldman MW, Freidlin PJ, Maki-Tanila A, Oortwijn M, Thomson P, Vignal A, Wimmers $\mathrm{K}$, Weigend S: Biodiversity of 52 chicken populations assessed by microsatellite typing of DNA pools. Genet Sel Evol 2003, 35(5):533-557.

18. Crooijmans RP, van Kampen AJ, van der Poel JJ, Groenen MA: Highly polymorphic microsatellite markers in poultry. Anim Genet 1993, 24(6): 44|-443.

19. Fumihito A, Miyake T, Takada M, Ohno S, Kondo N: The genetic link between the Chinese bamboo partridge (Bambusicola thoracica) and the chicken and junglefowls of the genus $\mathbf{G a l}-$ lus. Proc Natl Acad Sci U S A 1995, 92(24): I I053-I I 056.

20. Hudson RR, Slatkin M, Maddison WP: Estimation of levels of gene flow from DNA sequence data. Genetics 1992, I 32(2):583-589.

21. Jorde LB, Bamshad M, Rogers AR: Using mitochondrial and nuclear DNA markers to reconstruct human evolution. Bioessays 1998, 20(2): 126-136.

22. Oka T, Ino $Y$, Nomura K, Kawashima S, Kuwayama T, Hanada $\mathrm{H}$, Amano T, Takada M, Takahata N, Hayashi Y, Akishinonomiya F: Analysis of $m t D N A$ sequences shows Japanese native chickens have multiple origins. Anim Genet 2007, 38(3):287-293.

23. Loftus RT, MacHugh DE, Bradley DG, Sharp PM, Cunningham P: Evidence for two independent domestications of cattle. Proc Natl Acad Sci U S A 1994, 9I(7):2757-276I.

24. Giuffra E, Kijas JM, Amarger V, Carlborg O, Jeon JT, Andersson L: The origin of the domestic pig: independent domestication and subsequent introgression. Genetics 2000, 154(4): 1785- 179|.

25. Sambrook J, W. RD: Molecular Cloning, A laboratory manual. New York., Cold Spring Harbor Laboratory Press.; 2001.

26. Peakall R, Smouse PE: GENALEX 6: genetic analysis in Excel. Population genetic software for teaching and research. Molecular Ecology Notes 2006, 6:288-295.

27. Schneider S D. Roessli, L. Excoffier.: Arlequin: A software for population genetics data analysis. Ver. 2.000. edition. Geneva, Genetics and Biometry Lab, Dept. of Anthropology, University of Geneva; 2000 
28. GenBank [http://www.ncbi.nlm.nih.gov]

29. Thompson JD, Gibson TJ, Plewniak F, Jeanmougin F, Higgins DG: The CLUSTAL_X windows interface: flexible strategies for multiple sequence alignment aided by quality analysis tools. Nucleic Acids Res 1997, 25(24):4876-4882.

30. Nicholas KB, Nicholas HB]: Genedoc, a Tool for Editing and Annotating Multiple Sequence Alignments. Distributed by the author; 1997.

31. Felsenstein J: PHYLIP. Phylogeny interface package (version 3.2). Cladistics 1989, 5:164-166.

32. Kumar S, Tamura K, Nei M: MEGA3: Integrated software for Molecular Evolutionary Genetics Analysis and sequence alignment. Brief Bioinform 2004, 5(2): 150-163.

33. Posada D, Crandall KA: Modeltest: testing the model of DNA substitution. Bioinformatics 1998, 14:817-818.

34. Pond SLK, Frost SDW, Muse SV: HyPhy: hypothesis testing using phylogenies Bioinformatics. Bioinformatics 2005, 21:676-679.

35. Rozas J, Sanchez-DelBarrio JC, Messeguer X, Rozas R: DnaSP, DNA polymorphism analyses by the coalescent and other methods. Bioinformatics 2003, 19(1 8):2496-2497.

36. Network program [http://www.fluxus-technology.com/]

37. Tajima F: Statistical method for testing the neutral mutation hypothesis by DNA polymorphism. Genetics 1989, I 23(3):585-595.

38. Fu YX: Statistical tests of neutrality of mutations against population growth, hitchhiking and background selection. Genetics 1997, I 47(2): $915-925$.

39. Rogers $A R$, Harpending $H$ : Population growth makes waves in the distribution of pairwise genetic differences. Mol Biol Evol 1992, 9(3):552-569.

40. Harpending HC: Signature of ancient population growth in a low-resolution mitochondrial DNA mismatch distribution. Hum Biol 1994, 66(4):591-600.

4I. Cheng HH, Levin I, Vallejo RL, Khatib H, Dodgson JB, Crittenden LB, Hillel J: Development of a genetic map of the chicken with markers of high utility. Poult Sci 1995, 74(I I): I855-1874.

42. Crooijmans RP, van der Poel J], Groenen MA: Functional genes mapped on the chicken genome. Anim Genet 1995, 26(2):73-78.

43. Crooijmans RP, Dijkhof RJ, van der Poel JJ, Groenen MA: New microsatellite markers in chicken optimized for automated fluorescent genotyping. Anim Genet 1997, 28(6):427-437.

Publish with Biomed Central and every scientist can read your work free of charge

"BioMed Central will be the most significant development for disseminating the results of biomedical research in our lifetime. "

Sir Paul Nurse, Cancer Research UK

Your research papers will be:

- available free of charge to the entire biomedical community

- peer reviewed and published immediately upon acceptance

- cited in PubMed and archived on PubMed Central

- yours - you keep the copyright

Submit your manuscript here:

http://www.biomedcentral.com/info/publishing_adv.asp
BioMedcentral 